\section{Frame of Reference}

\author{
Sarah Fraser \\ Dalhousie Medicine, Class of 2014
}

what is this?

a straight line that a drunk man must tandem walk

or

peering down on a poster board from above

or

the shortest distance between two points

or

the middle part of capital ' $\mathrm{H}$ '

Normal EKG

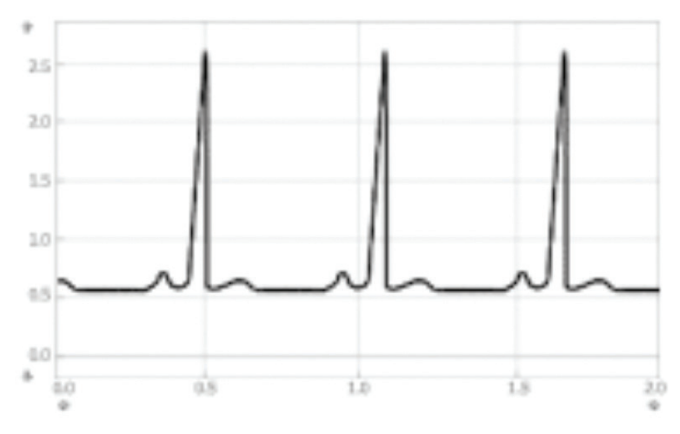

now - what is this?

it all depends on your frame of reference.

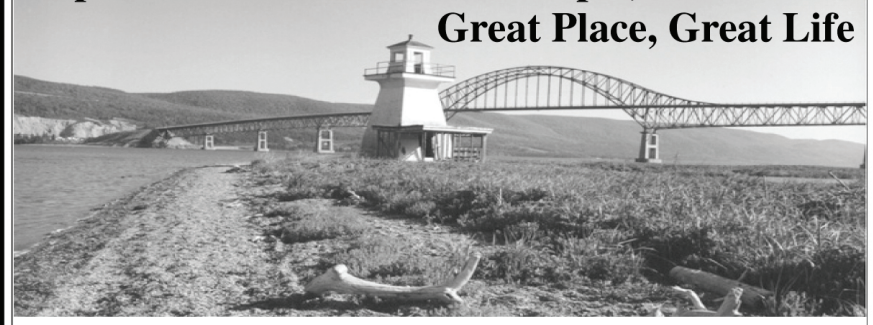

The Cape Breton District Health Authority has openings available in:

-Emergency Medicine

-Medical Oncology

-Pathology

-Radiology

-Family Medicine

-Palliative Care

-Psychiatry

-General Internal Medicine (interest in Rheumatology)

The District serves over 130,000 people through regional, community and rural hospitals, Continuing Care, Mental Health and Addiction Services, Public Health and the Cape Breton Cancer Centre. Cape Breton's unique beauty, diverse culture and year-round recreational opportunities make the Island a vibrant place to work and play.

All candidates must be certified by the Royal College of Physicians and Surgeons or the Canadian College of Family Physicians or equivalent and be eligible for licensure in the province of Nova Scotia.

Inquiries and applications to:

Dr. Rex Dunn, Vice President, Medicine

Cape Breton District Health Authority

1482 George Street, Sydney, Nova Scotia B1P 1P3

Fax: (902) 567-7255

E-mail: dunnr@cbdha.nshealth.ca

Website: www.cbdha.nshealth.ca

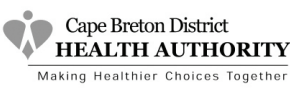

Live, werk and play an the Sauth Share

Imagine yourself kayaking, canoeing, sailing, whale watching, diving or enjoying one of our many golf courses, hiking trails, theatres, galleries or museums. We are located on Nova Scotia's South Shore (one hour from metro Halifax), where miles of coastline are marked by beautiful, sandy beaches and picturesque towns including Bridgewater, Chester, Liverpool, Lunenburg and Mahone Bay; where hundreds of lakes, streams and rivers flow through small fishing villages and dense forests.

The District requires physicians for:

- Family Medicine (locations include Bridgewater, Caledonia, Chester, Lunenburg and Mahone Bay)

- Emergency Medicine

- Psychiatry - Bridgewater

- Walk-in Clinic - Bridgewater

- Locum opportunities available

Candidates must be eligible for licensure in Nova Scotia.

Inquiries and applications may be directed to: Dr. Peter Vaughan, VP Medicine South Shore District Health Authority 90 Glen Allan Drive Bridgewater NS B4V 3S6 Canada

Telephone: $902-527-5057$

Fax: 902-527-5269

E-mail: pvaughan@ssdha.nshealth.ca

Website: www.southshorehealth.ca 